\title{
PYRIDOXINE DEFICIENCY IN HUMAN BEINGS INDUCED WITH DESOXYPYRIDOXINE ${ }^{1}$
}

\author{
By JOHN F. MUELLER AND RICHARD W. VILTER
}

(From the Department of Internal Medicine, University of Cincinnati, Cincinnati, Ohio)

(Received for publication July 21, 1949)

In 1934 György (1) announced the existence of an essential vitamin for the rat which was distinct from vitamins $\mathrm{B} 1$ and $\mathrm{B} 2$. He called it the "antiacrodynia" factor. For a while it carried the name "Adermin" because rats deficient in this substance developed dermatitis, but after its synthesis in 1939 by Harris and Folkers (2) it was renamed pyridoxine. Thereafter numerous reports appeared concerning deficiency states in various animals deprived of this essential nutrient. Deprivation experiments in human beings have not produced clear-cut clinical results and human pyridoxine requirements are unknown.

On a pyridoxine deficient diet young rats develop a seborrhea-like dermatitis and in addition convulsive seizures, muscular weakness (3), decrease in lymphoid tissue (4), and decreased circulating antibodies (5). Puppies on such a diet develop a hypochromic anemia which responds specifically to pyridoxine (6). Swine also develop anemia, but in addition have epileptiform seizures and abnormalities of gait accompanied by lesions of the central nervous system (7). Monkeys in addition to weight loss and weakness develop a lymphocytopenia and an absolute increase in neutrophiles (8).

It was only natural that many investigators should attempt to put this vitamin to a therapeutic trial against human ailments which were similar to the manifestations of pyridoxine deficiency in animals. Pehl (9) used pyridoxine in seborrheic dermatitis of children with little effect. Later Jolliffe, Rosenblum and Sawhill (10) treated acne vulgaris and Wright, Samitz and Brown (11) treated seborrhea, atopic eczema and other eczematoid lesions with vitamin B6. Jolliffe (12) and independently Rudesill and Weigand (13) used pyridoxine in Parkinson's disease and Antopol and Schotland (14) treated patients afflicted with

1 This study was aided by a grant from Merck and Co., Inc., Rahway, New Jersey, and the Robert Gould Research Foundation, Inc. pseudohypertrophic muscular dystrophy with this same material. Vilter, Schiro and Spies (15) reported an increase in the number of circulating leucocytes in patients with pellagra and pernicious anemia who received pyridoxine and later Cantor and Scott (16) reported similar results in patients with agranulocytosis. Many enthusiastic reports have been published concerning the therapeutic value of pyridoxine in women with nausea of pregnancy (17) and patients with post-irradiation sickness (18). Although all of these reports were encouraging, none have withstood the test of time.

A more specific effect in nutritionally deficient persons was reported by Spies, Bean, and Ashe (19) who gave pyridoxine to patients previously treated with other members of the vitamin B-complex but who still had symptoms of weakness, insomnia, nervousness, irritability and difficulty in walking. These symptoms were alleviated immediately by pyridoxine. Later Smith and Martin (20) reported on cheilosis successfully treated with synthetic vitamin B6. In 1948 an experimental study was reported by Hawkins and Barsky (21) on a human volunteer placed on a vitamin B6 deficient diet for 54 days. The authors were unable to state unequivocally that any specific changes occurred.

Not only have the clinical aspects of pyridoxine deficiency in animals been described but the pathological-physiology of pyridoxine deprivation has received considerable attention. There is good evidence that pyridoxine and the members of the vitamin B6 complex which occur in foods, pyridoxal and pyridoxamine, function as codecarboxylases (22) and transaminases (23) in animal metabolism. In addition pyridoxine seems to be necessary for the conversion of tryptophane to niacin (24) and pyridoxine deficient dogs excrete large amounts of xanthurenic acid and kinurenic acid when fed tryptophane (25). Such observations link pyridoxine to the metabolism of tryptophane and other amino acids. There is also some 
evidence that pyridoxine has a role in fat metabolism (26).

With the recent introduction of vitamin analogues, which are fully discussed in an excellent monograph by Wooley (27), a new tool is available to the investigator with which to study deficiency disease. Ott (28) reported on the antipyridoxine activity of one of these antimetabolites, desoxypyridoxine, and found the inhibitory ratio to be $2: 1$ in chicks. Mushett, Stebbins and Barton (29) have reported a study of pathologic changes resulting from growth reversal by this compound and found that these changes were similar to those found in pyridoxine deficient animals, the chick, puppies, and monkeys. Stoerk (30) reported that lymphosarcoma transplants failed to grow in mice on a pyridoxine deficient diet and that these implants regressed when mice were placed on a deficient diet and desoxypyridoxine was added to the regimen.

Gellhorn and Jones (31) reported on the use of desoxypyridoxine plus a pyridoxine deficient diet in six patients with lymphosarcoma or leukemia. Although two of their patients had toxic reactions in the form of convulsions after large doses of desoxypyridoxine, ${ }^{2}$ they did not observe any symptoms or signs which could be attributed specifically to a deficiency of pyridoxine.

We also were interested in desoxypyridoxine as an agent which might possibly control lymphoid tumors in human beings. However, prior to such trials we wished to determine what would happen to non-cancerous patients treated with this material. During such a pilot experiment we observed a syndrome in human beings precipitated by a vitamin B-complex poor diet and desoxypyridoxine, and which responds rapidly and specifically to the administration of pyridoxine hydrochloride. These early experiments have been extended and are the basis of this report.

\section{MATERIALS AND METHODS}

When this investigation was undertaken we were not aware that desoxypyridoxine had been used in human beings. Tests for toxicity were performed using patients who were eating the regular hospital diet. They were given $1 \mathrm{mg}$. intramuscularly and the dose was gradually increased to $50 \mathrm{mgs}$. These trials were repeated on patients placed on a standard vitamin B-complex poor diet

\footnotetext{
2 Reported also by Hoster and Zanes in a personal communication.
}

which has an average composition as follows: calories, 3,127; protein, $41.7 \mathrm{gms}$; fat, $27 \mathrm{gms}$.; thiamine, $0.42 \mathrm{mg}$.; niacin $4.2 \mathrm{mgs}$; riboflavin, $0.60 \mathrm{mg}$. (calculated from Bowes and Church, 1946) ; and pyridoxine, $0.5 \mathrm{mg}$. (estimated). ${ }^{3}$ This diet is not sufficiently restricted to induce clinical signs of niacin, thiamine, or riboflavin deficiency. Patients with signs of pellagra, beriberi or riboflavin deficiency maintained on this diet for three to six weeks either show no change in subjective or objective signs or improve. There were no untoward effects noted in either group of patients.

Eight patients, seven whites and one negro, were chosen who had been hospitalized for various chronic illnesses. The distribution of these illnesses was as follows: rheumatoid arthritis, two; post-encephalitic Parkinsonism, two; disseminated sclerosis, one; fractured leg, one; tabes dorsalis, one; osteo-arthritis, one. They varied in ages from 27 to 87 . They were divided into two experimental groups. The first group received the vitamin B-complex poor diet and $60 \mathrm{mgs}$. of desoxypyridoxine intramuscularly each day. The second group received the same diet and $100 \mathrm{mgs}$. of desoxypyridoxine which was later increased to $125 \mathrm{mgs}$. and then $150 \mathrm{mgs}$. each day. One patient received succinyl sulfathiazole, 6 gms. each day by mouth.

The patients were observed each day for any physical abnormality by the resident staff and three times a week by one of us until lesions occurred and daily thereafter. Erythrocyte, total and differential leucocyte, platelet, and reticulocyte counts, hemoglobin levels and hematocrit determinations were performed at weekly intervals and total and differential leucocyte counts at three to four day intervals on the first group. Weekly total and differential leucocyte counts were done on the second group in addition to complete hematological studies which were performed before and after the experimental period. Twenty-four hour urine specimens were collected before the regimen was begun and weekly thereafter. They were analyzed quantitatively for pyridoxic acid according to a modification of the method of Huff and Perlzweig which was generously reported to us in a personal communication by Dr. Herbert P. Sarett (32). In addition quantitative assays for thiamine (33), $\mathrm{N}^{1}$ methylnicotinamide (34), and riboflavin (35) and a qualitative test for xanthurenic acid (36) were performed.

All but one of the patients who developed symptoms and signs ascribable to the experimental regime were given a vitamin mixture containing thiamine $25 \mathrm{mgs}$., niacinamide $50 \mathrm{mgs}$. , and riboflavin $10 \mathrm{mgs}$. intramuscularly for four to five days. Finally they were given 100-200 mgs. of pyridoxine intramuscularly depending on the severity of the clinical conditions. One patient received pyridoxine without prior therapy with the other B-complex vitamins. In all instances the vitamin B-complex poor diet and the desoxypyridoxine were continued throughout the entire experiment. All medications were given parenterally.

3 This is the diet used in all patients in this report where reference is made to "Vitamin B-complex poor diet." 


\section{RESULTS}

Of the four patients who received $60 \mathrm{mgs}$. of desoxypyridoxine, two developed superficial scaling, oily, reddened skin lesions of pronounced degree about the eyes, nose and mouth, and one developed similar but much less extensive dermatitis. In addition fissures like those seen in persons with riboflavin deficiency appeared at the angles of the mouth and lateral canthi of the eyes in the first two patients. Their tongues and buccal mucous membranes also became sore, swollen and red and resembled the glossitis of niacin deficiency. These lesions appeared even though the riboflavin, $\mathrm{N}^{1}$ methylnicotinamide and thiamine levels in the urine were in the low normal range. (See Table I.) These lesions occurred in 19-21 days after starting the deprivation experiment. Only slight improvement in the burning sensation of the tongue but no objective improvement followed the administration of the B-complex mixture. All the lesions disappeared in 48-72 hours after the administration of $100 \mathrm{mgs}$. pyridoxine daily whether the B-complex vitamins had been given previously or not.

In the second group of four patients who received $100 \mathrm{mgs}$. of desoxypyridoxine one patient developed severe and extensive skin lesions identical with those described above and an itching erythematous eruption on the arms and legs. In addition she developed a severe systemic reaction consisting of nausea, vomiting, extreme weakness and dizziness which appeared while she was getting the mixture of B-complex vitamins and which necessitated immediate treatment with pyridoxine. The skin lesions appeared in ten days and the systemic reaction in 16 days after desoxypyridoxine was administered but both responded dramatically within 12-24 hours after the parenteral injection of $100 \mathrm{mgs}$. of pyridoxine twice a day. Only pigmentation at the sites of the skin lesions remained after 96 hours. Of the other three patients all developed one type of lesion or the other but to a much milder degree. One patient developed an acute glossitis on the 21st day of the experiment which spontaneously regressed. Another had rapid extension of preexisting seborrhea which, however, remitted before treatment with pyridoxine was begun. The post-encephalitic Parkinsonism from which this patient was suffer-
TABLE I

Urinary excretion levels of members of the vitamin B-complex from eight patients before and two to four weeks after the administration of desoxypyridoxine and $a$ vitamin $B$ poor diet

\begin{tabular}{|c|c|c|c|c|}
\hline Patient & $\begin{array}{c}\text { Pyridoxic } \\
\text { acid }\end{array}$ & Thiamine & $\begin{array}{l}N^{2} \text { methyl- } \\
\text { nicotinamide }\end{array}$ & Riboflavin \\
\hline $\begin{array}{l}\text { M. B. } \\
\text { Before D* } \\
\text { After D }\end{array}$ & $\begin{array}{c}\begin{array}{c}\text { mgs./24 } \\
\text { hours }\end{array} \\
\\
6.720 \\
8.000\end{array}$ & $\begin{array}{c}\text { mgs. } / 24 \\
\text { hours }\end{array}$ & $\begin{array}{c}\mathrm{mgs} . / 24 \\
\text { hours }\end{array}$ & $\begin{array}{c}\text { mgs./24 } \\
\text { hours } \\
\\
0.50 \\
0.70\end{array}$ \\
\hline $\begin{array}{l}\text { H. P. } \\
\text { Before D } \\
\text { After D }\end{array}$ & $\begin{array}{l}5.939 \\
6.560\end{array}$ & .418 & 2.9 & 2.0 \\
\hline $\begin{array}{l}\text { E. S. } \\
\text { Before D } \\
\text { After D }\end{array}$ & $\begin{array}{l}5.740 \\
3.320\end{array}$ & 0.182 & 4.1 & 0.87 \\
\hline $\begin{array}{l}\text { H. H. } \\
\text { Before D } \\
\text { After D }\end{array}$ & $\begin{array}{l}1.212 \\
3.912\end{array}$ & 0.108 & 1.5 & 0.84 \\
\hline $\begin{array}{l}\text { L. K. } \\
\text { Before D } \\
\text { After D }\end{array}$ & $\begin{array}{l}2.576 \\
2.306\end{array}$ & 0.137 & 1.00 & 0.951 \\
\hline $\begin{array}{l}\text { R. W. } \\
\text { Before } D \\
\text { After D }\end{array}$ & $\begin{array}{l}7.800 \\
2.556\end{array}$ & 0.216 & & $\begin{array}{l}2.9 \\
1.8\end{array}$ \\
\hline $\begin{array}{l}\text { L. L. } \\
\text { Before D } \\
\text { After D }\end{array}$ & $\begin{array}{l}0.685 \\
1.997\end{array}$ & 0.088 & & $\begin{array}{l}0.4 \\
1.50\end{array}$ \\
\hline $\begin{array}{l}\text { J. M. } \\
\text { Before D } \\
\text { After D }\end{array}$ & $\begin{array}{l}0.824 \\
3.080\end{array}$ & 0.131 & & $\begin{array}{l}0.80 \\
1.50\end{array}$ \\
\hline
\end{tabular}

* Desoxypyridoxine.

ing progressed during the deprivation experiment and then regressed without any change in the regimen. The third patient developed severe pruritus of the face with a mild seborrheic dermatitis on the 20th day which responded well to pyridoxine within 48 hours. The last three patients all received $125 \mathrm{mgs}$. and then $150 \mathrm{mgs}$. a day of desoxypyridoxine during the last week prior to the administration of pyridoxine with no apparent increase in the severity of the lesions.

The hematologic status of the patients was followed very closely. No anemia was found except in one patient, L. K., who received succinyl sulfathiazole in addition to the routine regimen. He developed macrocytic anemia which responded to folic acid. In no instance were hypochromia or siderocytosis noted. The leucocyte counts varied greatly, but leucopenia was not observed in any patient. In seven patients there was a mild, 
TABLE II

\section{Total leucocyte, lymphocyte and neutrophile counts of eight patients before and two to four weeks after the administration of desoxypyridoxine and $a$ vitamin $B$ poor diet. In six patients these counts were repeated after the administration of pyridoxine}

\begin{tabular}{|c|c|c|c|}
\hline Patient & $\begin{array}{c}\text { Total WBC } \\
\text { per c.mm. }\end{array}$ & $\begin{array}{l}\text { Total lympho- } \\
\text { cytes per } \\
\text { c.mm. }\end{array}$ & $\begin{array}{l}\text { Total neutro- } \\
\text { phile count } \\
\text { per c.mm. }\end{array}$ \\
\hline $\begin{array}{l}\text { M. B. } \\
\text { Before D* } \\
\text { After D } \\
\text { After P† }\end{array}$ & $\begin{array}{l}5000 \\
5000 \\
5500\end{array}$ & $\begin{array}{r}1200 \\
1200 \\
990\end{array}$ & $\begin{array}{l}3100 \\
2950 \\
3850\end{array}$ \\
\hline $\begin{array}{l}\text { H. P. } \\
\text { Before D } \\
\text { After D } \\
\text { After P }\end{array}$ & $\begin{array}{l}8400 \\
8500 \\
7650\end{array}$ & $\begin{array}{r}2680 \\
935 \\
1850\end{array}$ & $\begin{array}{l}4150 \\
5525 t \\
4650\end{array}$ \\
\hline $\begin{array}{l}\text { E. S. } \\
\text { Before D } \\
\text { After D } \\
\text { After P }\end{array}$ & $\begin{array}{r}10,600 \\
8600 \\
10,700\end{array}$ & $\begin{array}{l}3600 \\
1462 \\
1400\end{array}$ & $\begin{array}{l}6455 \\
6280 \\
8450\end{array}$ \\
\hline $\begin{array}{l}\text { H. H. } \\
\text { Before D } \\
\text { After D }\end{array}$ & $\begin{array}{l}7350 \\
8200\end{array}$ & $\begin{array}{r}1690 \\
700\end{array}$ & $\begin{array}{l}4850 \\
6300\end{array}$ \\
\hline $\begin{array}{l}\text { L. K. } \\
\text { Before D } \\
\text { After D }\end{array}$ & $\begin{array}{l}6750 \\
5800\end{array}$ & $\begin{array}{l}1890 \\
1045\end{array}$ & $\begin{array}{l}4185 \\
3600\end{array}$ \\
\hline $\begin{array}{l}\text { R. W. } \\
\text { Before D } \\
\text { After D } \\
\text { After P }\end{array}$ & $\begin{array}{l}5150 \\
5650 \\
6650\end{array}$ & $\begin{array}{l}1750 \\
1075 \\
1795\end{array}$ & $\begin{array}{l}3090 \\
3500 \\
4055\end{array}$ \\
\hline $\begin{array}{l}\text { L. L. } \\
\text { Before D } \\
\text { After D } \\
\text { After P }\end{array}$ & $\begin{array}{l}5750 \\
4650 \\
5750\end{array}$ & $\begin{array}{l}1955 \\
1255 \\
1895\end{array}$ & $\begin{array}{l}2930 \\
2790 \\
3220\end{array}$ \\
\hline $\begin{array}{l}\text { J. M. } \\
\text { Before D } \\
\text { After D } \\
\text { After P }\end{array}$ & $\begin{array}{l}6200 \\
5750 \\
6850\end{array}$ & $\begin{array}{l}2045 \\
1265 \\
1575\end{array}$ & $\begin{array}{l}3530 \\
3335 \\
4815\end{array}$ \\
\hline
\end{tabular}

* Desoxypyridoxine.

$\uparrow$ Pyridoxine.

$\ddagger$ H. P. had 1105 eosinophiles on this day.

absolute lymphocytopenia. Two patients developed eosinophilia of $22 \%$ and $9 \%$ respectively at the height of their rash which fell following the administration of pyridoxine. (See Table II.)

As stated before, the urinary levels for thiamine, $\mathrm{N}^{1}$ methylnicotinamide and riboflavin were in the low normal range. (See Table I.) The values for pyridoxic acid were so variable from week to week that we are unable to interpret them as yet. One point that deserves mention is that early in the experiment the urine levels of pyridoxic acid semed to rise as though replacement of cellular pyridoxine was occurring. No xanthurenic acid nor kynurenin was found in the urine of any patient as tested qualitatively using the method referred to previously. ${ }^{4}$

None of these patients had sufficient lymphadenopathy at the start of the experiment to enable one to evaluate atrophy of these structures, but several different observers noted an increase in the size of the lymph nodes following the institution of the pyridoxine therapy.

In view of a recent paper by Rinehart and Greenberg (37) concerning pyridoxine deficiency in monkeys precipitated by a pyridoxine-free diet, wherein arteriosclerotic changes in the blood vessels of those animals on the diet were much greater than in the control group of monkeys, blood cholesterol levels were determined on three patients at the height of their deficiency state. All values were in the normal range.

\section{PROTOCOLS}

M. B., a 37-year-old unmarried colored girl with a primary diagnosis of inactive rheumatoid arthritis, was placed on the B-complex poor diet on May 12, 1949. Two days later and each day thereafter $100 \mathrm{mgs}$. of desoxypyridoxine were administered intramuscularly. On May 24, 1949 the patient began to complain of pruritus of the arms and legs. Examination revealed a discreet papular eruption on the extensor surfaces of both forearms and the anterior surfaces of both lower legs. A few small reddened papillae were present on the lateral margins of the tongue. By May 27, 1949 the patient had developed lesions about the angles of the nose, the eyes and mouth which were characterized by excoriation, redness, desquamation of superficial epithelium and oiliness. By the next day most of the face was involved by this seborrhea-like process (Figure 1). On May 28, 1949 she was started on a vitamin mixture given parenterally each day and consisting of $25 \mathrm{mgs}$. of thiamine, $50 \mathrm{mgs}$. of niacinamide, and $10 \mathrm{mgs}$. of riboflavin. There was no improvement in the skin or tongue lesions. On the evening of May 30, 1949 the patient noted the onset of rather severe nausea, vomiting, dizziness, weakness and feeling of impending disaster. She was awake all night and refused food the next morning. The skin lesions were even more extensive on the face and a diffuse erythema surrounded the papular lesions on the extremities. The tongue was swollen and red-

4 Since completion of the experiment a quantitative method for measuring xanthurenic acid in the urine has been adopted by us. It has been found that individuals receiving desoxypyridoxine and the vitamin B-complex poor diet excrete normal amounts of xanthurenic acid except after a test load of tryptophane when these levels go up tremendously but quickly return to normal after 48 hours. However, this response to tryptophane can be prevented by the administration of pyridoxine. 
dened. Pyridoxine was given in doses of $100 \mathrm{mgs}$. intramuscularly twice a day. The remainder of the regimen including desoxypyridoxine was not altered. In six hours the patient noted improvement in her feeling of well-being. By the next morning all the nausea and vomiting had disappeared, and she felt stronger. The skin lesions were unchanged. Within 48 hours the patient had no subjective complaints and the skin lesions were regressing. The tongue was normal. By 96 hours, the face was entirely free of all lesions except for some residual pigmentation. The extremities were clear, and the tongue was normal.

H. H., a 64-year-old white man with a primary diagnosis of tabes dorsalis, was started on the vitamin Bcomplex poor diet on March 15, 1949 and four days later on $60 \mathrm{mgs}$. of desoxypyridoxine daily. On April 5, the patient complained of mild weakness. The next day a rash was noted on the patient's face localized about the corners of the mouth and the folds of the nose. The lesions were red and scaling. These lesions were mild compared to the others; the tongue and mucous membranes were normal. Without any change in the regimen the lesions began to fade and by April 16, 1949 they had disappeared completely. The desoxypyridoxine was increased to 80 mgs. per day and continued for another month with no further changes noted in the patient.

E. S., a 43-year-old white man with bilateral leg fractures, was started on the vitamin B-complex poor diet on March 15, 1949 and four days later on $60 \mathrm{mgs}$. of desoxypyridoxine daily. On April 5, 1949 the patient first noted burning and pruritus of the face which was followed by the appearance of lesions located about the canthi of the eyes, the chin and the folds of the nose which were red, scaling and involved some of the hair follicles. The tongue was normal. It was noted that the lesions resembled previously described lesions of riboflavin deficiency. The dermatitis continued to progress and on April 9, 1949 the patient complained of some burning of the tongue. Examination revealed a reddened tip, but no papillary atrophy. Burning of the face was severe. There were no other complaints and the appetite was good. On April 16, 1949 the patient was started on the vitamin mixture previously described. There seemed to

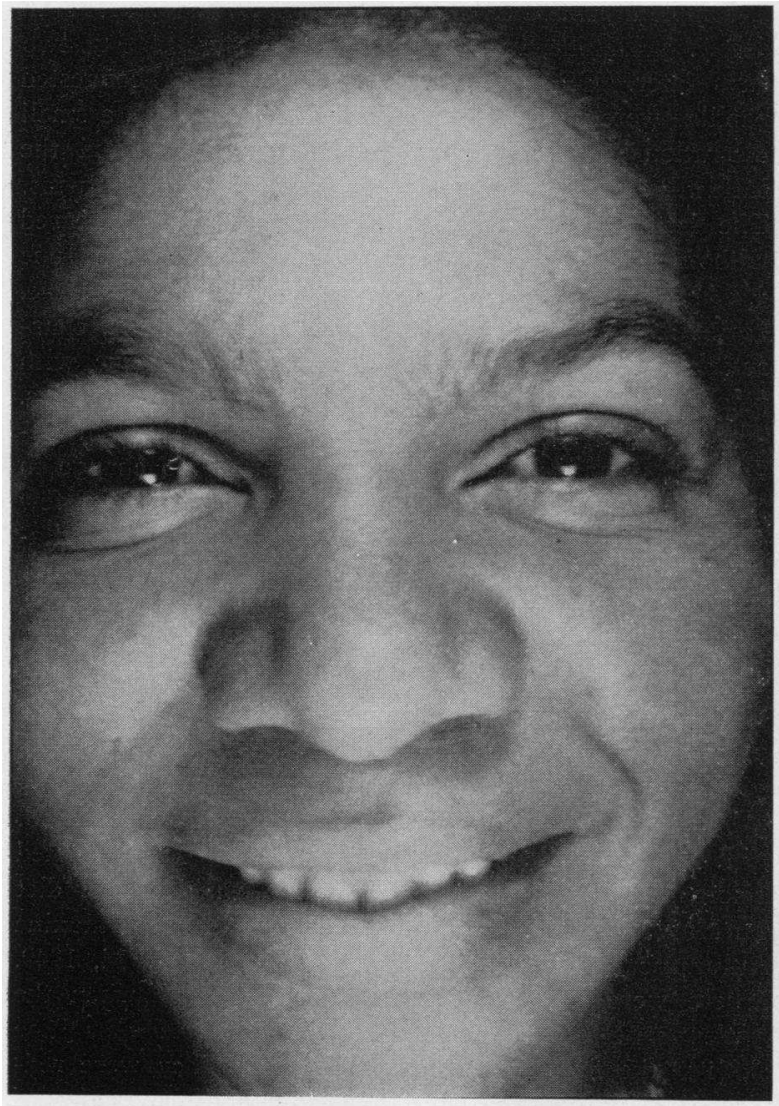

A

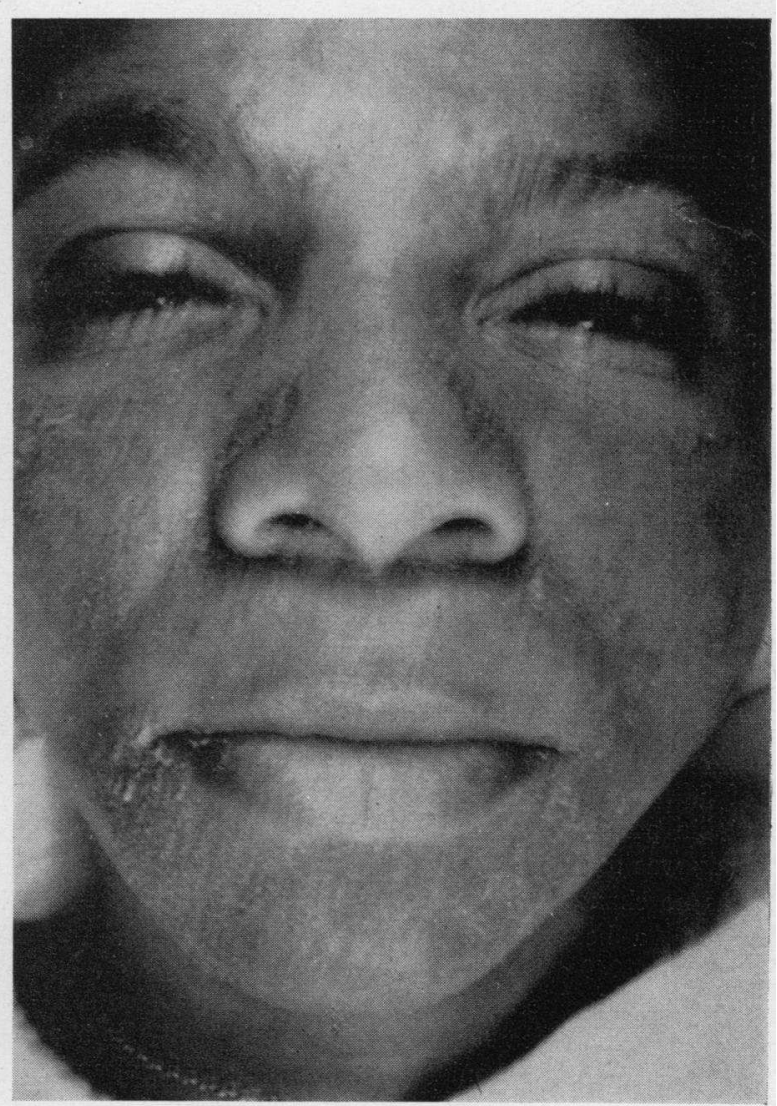

B

FIG. 1.

(A) Before the administration of desoxypyridoxine and (B) at the height of the scaling seborrhea-like dermatitis induced by the administration of desoxypyridoxine. The lesions were not affected by the administration of niacin amide, thiamine, and riboflavin but disappeared after 96 hours of therapy with pyridoxine. 
be some improvement in the burning sensations in the tongue, but the rash was unchanged. On April 21, 1949 pyridoxine, $100 \mathrm{mgs}$. intramuscularly daily, was begun. In 48 hours there was great improvement in the lesions of the face and within another 24 hours the skin of the face was essentially healed. The tongue appeared normal.

H. P., a 47-year-old white man with inactive rheumatoid arthritis, was started on the vitamin B-complex poor diet on March 15, 1949 and $60 \mathrm{mgs}$. of desoxypyridoxine intramuscularly daily was begun on March 19, 1949. On April 2, 1949 the patient noted cracks in the angles of his mouth and by the next day a diffuse, pruritic, burning rash had appeared involving the corners of the mouth, nose and eyes. On April 5, 1949 these lesions had become reddened, excoriated, and moist. Reddened papular lesions had appeared on the chin. The mucous membrane of the lower lip revealed a circumscribed grayish placque which later became macerated. The tongue revealed a few reddened papillae on the lateral margins. By April 7, 1949 blotchy areas of dermatitis had appeared all over the face. There was some facial edema. The lesions on the chin were beginning to desquamate. By April 12, 1949 some of the redness was gone, but the skin of the face had begun to scale. The tongue was unchanged. The patient was started on $100 \mathrm{mgs}$. of pyridoxine; the desoxypyridoxine dosage was maintained. Within 48 hours there was great improvement in the lesions. The redness and excoriation about the eyes had disappeared. The lesion on the mucous membrane of the lip was healing. The tongue was normal. In another 48 hours the face was normal. At the height of the rash this patient had a peripheral blood eosinophilia of $22 \%$ which fell to a normal value within 72 hours after pyridoxine was begun.

L. K., an 87-year-old white man with no specific complaints other than osteo-arthritis of the spine, was placed on the vitamin B-complex poor diet and desoxypyridoxine intramuscularly daily on Jan. 31, 1949. The latter medication was used in increasing doses, starting with $10 \mathrm{mgs}$. each day and finally ending with $80 \mathrm{mgs}$. each day. On March 1, 1949 succinyl sulfathiazole in 6 gms. daily oral doses was given with the hope of decreasing the bacterial flora of his intestine which might be providing some pyridoxine. By May 5, 1949 there had been no objective or subjective changes other than a mild macrocytic anemia of 3,000,000 erythrocytes per c. mm., 12 gms. of hemoglobin per $100 \mathrm{cc}$. and a hematocrit of $36 \%$. The sulfa drug was discontinued and in a period of two weeks there was no change. However, when folic acid was given by mouth, a hematological response occurred. Finally on May 27, 1949 after nearly four months of the diet and the desoxypyridoxine, the study was discontinued.

R. W., a 27-year-old white male suffering from postencephalitic Parkinsonism, was started on the vitamin Bcomplex poor diet on May 12, 1949 and desoxypyridoxine, 100 mgs. intramuscularly per day, was administered two days later. This patient had rather marked seborrhea of the scalp and minimal lesions of the same nature about the forehead prior to the institution of the experimental regime. On May 27, 1949 a small yellowish placque ap- peared on the mucous membrane of the lower lip. This lesion never progressed. On May 31, 1949 the seborrheic lesions already present on the forehead had become appreciably worse and had involved the folds of the nose and the canthi of the eyes. However, by June 3, 1949 the lesions had improved though the regimen had not been changed. The supplementary vitamins were begun and the desoxypyridoxine was increased to $125 \mathrm{mgs}$. on June 6, 1949. On June 10, 1949 the patient's Parkinsonism which previously had been unaffected became much worse and that night while walking he inadvertently crashed into a window and sustained lacerations to the face and neck. However, by the next day the Parkinsonism seemed to improve again without any change in the program. On June 11, 1949 the desoxypyridoxine was increased to $150 \mathrm{mgs}$. q.d. There was no further change. The skin lesions were minimal. On June 14, 1949 pyridoxine $100 \mathrm{mgs}$. twice daily was started. The lesions were so mild that any critical evaluation of the therapy was impossible. There was no further change, however, in the patient's paralysis-agitans.

L. L., a 40-year-old white woman afflicted with postencephalitic Parkinsonism, was placed on the vitamin B-complex poor diet on May 12, 1949 and started on desoxypyridoxine, $100 \mathrm{mgs}$. intramuscularly each day, two days later. On May 27, 1949 a few small congested papillae were noted on the margins of the tongue, a small ulceration was present on the buccal mucosa, and the patient wás complaining of pruritus of both forearms. The latter two abnormalities subsequently disappeared without any change in the program. However, on June 4, 1949 the patient complained of burning of the tongue. On examination the patient had an acute glossitis, characterized by a swollen, diffusely reddened tongue with patchy areas of congested papillae along the margins. The glossitis resembled that seen in acute niacin deficiency. Again, however, with absolutely no change in the regimen, the glossitis improved leaving only a few congested papillae behind. So on June 6, 1949 the vitamin supplements were begun and the desoxypyridoxine increased to $125 \mathrm{mgs}$. and later to $150 \mathrm{mgs}$. on June 11 , 1949 with no further changes. On June 14, 1949 pyridoxine, $100 \mathrm{mgs}$. twice daily, was begun. There were no objective nor subjective changes noted in the severity of the Parkinsonism before or after the pyridoxine was given. The few congested papillae on the tongue disappeared 48 hours after the pyridoxine was administered.

J. M., a 35-year-old white man with disseminated sclerosis, was placed on the vitamin B-complex poor diet on May 12, 1949. One hundred mgs. of desoxypyridoxine intramuscularly each day was started on May 14, 1949. There were no changes until May 31, 1949 when the patient first complained of pruritus of the face. On June 3, 1949 the first skin lesions appeared. They were reddened, scaling lesions about the chin and the angles of the nose. The pruritus of the face became severe. Vitamin supplements were begun on June 6,1949 at which time the desoxypyridoxine was increased to $125 \mathrm{mgs}$. daily. June 11, 1949 there was slight progression of the skin lesions and the burning and pruritus of the face was 
unchanged. The desoxypyridoxine was increased to 150 mgs. daily. On June 13, 1949 a cheilotic lesion appeared in the left corner of the mouth. The tongue and mucous membranes were normal. Pyridoxine, $100 \mathrm{mgs}$. twice daily, was started on June 14, 1949. Within 48 hours itching had stopped and in another 24 hours the face was free of lesions. The cheilotic lesion was better but had not disappeared. After 96 hours it too had healed.

\section{DISCUSSION}

The administration of a pyridoxine antagonist, desoxypyridoxine, in conjunction with a diet deficient in all members of the vitamin B-complex has facilitated the study of pyridoxine deficiency in human beings. The seborrhea-like skin lesions, the glossitis, stomatitis and cheilosis failed to respond to niacinamide, thiamine, and riboflavin, but did respond dramatically when pyridoxine was given. Since rapid improvement occurred following the administration of pyridoxine in addition to the antagonist, an antimetabolic effect rather than a simple drug reaction is demonstrated for desoxypyridoxine.

Pyridoxine neutralized the effect of desoxypyridoxine whether or not there had been prior administration of other B-complex vitamins, indicating considerable specificity of action for vitamin B6. Similar lesions have never been observed by us in patients maintained for weeks or months on the same deficient diet which was used in this experiment. Thus the possibility can be eliminated that the diet alone was responsible for the lesions.

It is interesting that these patients developed seborrheic dermatitis, because the dermatitis which occurs in pyridoxine deficient rats is said to be seborrhea-like and the common seborrhea of humans has been said to respond to pyridoxine. However, there is no evidence as yet that human seborrhea is related in any way to pyridoxine deficiency, either primary or conditioned.

The occurrence of evanescent symptoms and signs of pyridoxine lack in some of our experimental subjects and the great variation in the severity of the clinical manifestation in different subjects are typical of all nutritional deficiency diseases. The striking similarity of the lesions about the eyes and lips to riboflavin deficiency and those of the tongue to niacin deficiency suggest a chemical relationship of pyridoxine to the other members of the vitamin B-complex.
The subjects who developed the most severe manifestations of deficiency disease in this experiment were those with rheumatoid arthritis. One may assume that the reason for this was accelerated metabolism or decreased utilization of available vitamins in these persons due to the chronic illness. Conversely, the two elderly patients developed few clinical manifestations. These observations are also in accord with our knowledge of naturally occurring deficiency states.

In this preliminary study we did not make an attempt to determine the inhibition index of desoxypyridoxine in human subjects. However, we do feel that the lesions produced are specific enough to use as the critical point for such an experiment. From these studies the ratio appears to be at least $1: 1$, and probably much higher.

Under the conditions of this experiment abnormal signs and symptoms have been induced in human beings with the aid of a pyridoxine antagonist, desoxypyridoxine. We believe that this state is equivalent to pyridoxine deficiency. The relationship of this deficiency state to carbohydrate, protein, and fat metabolism and to other B-complex deficiency diseases; to pathologic changes in the skin and lymphoid tissues; and to the growth and development of normal and abnormal cells is under investigation.

\section{SUMMARY AND CONCLUSIONS}

1. Desoxypyridoxine, an analogue and metabolic antagonist of pyridoxine has been given intramuscularly in doses of $60-150 \mathrm{mgs}$. to eight patients on a vitamin B-complex poor diet.

2. Seborrhea-like skin lesions developed about the eyes, nose and mouth after two to three weeks. Erosions appeared in and about the mouth resembling cheilosis of riboflavin deficiency. Glossitis and stomatitis similar morphologically to the lesions of niacin deficiency were noted in about one half of the patients. One patient developed severe systemic symptoms; nausea, vomiting, weakness and dizziness.

3. The skin, mucous membrane and systemic manifestations were unchanged when a mixture containing thiamine, riboflavin and niacinamide was given but disappeared within 48-72 hours after pyridoxine was administered.

4. The inhibitory ratio of antimetabolite to me- 
tabolite in human beings was not accurately measured but is at least $1: 1$.

5. The similarity of the oral lesions to those frequently found in niacin and riboflavin deficiency bespeaks a close metabolic relationship between pyridoxine, niacin and riboflavin.

6. The authors believe that these lesions constitute at least part of the human syndrome of acute pyridoxine deficiency.

\section{ACKNOWLEDGMENTS}

We wish to acknowledge the technical assistance of Miss Virginia Hawkins, Mrs. Betty Fichter and Mrs. Helen Glazer and to thank Dr. A. Gibson of Merck and Co., Inc., for the generous supply of desoxypyridoxine.

\section{BIBLIOGRAPHY}

1. György, P., Investigations on vitamin B2 complex; differentiation of lactoflavin and "rat antipellagra" factor. Biochem. J., 1935, 29, 741.

2. Harris, S. A., and Folkers, K., Synthetic vitamin B6. Science, 1939, 89, 347.

3. György, P., and Eckardt, R. E., Vitamin B6 and skin lesions in rats. Nature, 1939, 144, 512.

4. Stoerk, H. C., Effects of calcium deficiency and pyridoxin deficiency on thymic atrophy (accidental involution). Proc. Soc. Exper. Biol. \& Med., 1946, 62, 90.

5. Stoerk, H. C., and Eisen, H. N., Suppression of circulating antibodies in pyridoxin deficiency. Proc. Soc. Exper. Biol. \& Med., 1946, 62, 88.

6. Fouts, P. J., Helmer, O. M., Lepkovsky, S., and Jukes, T. H., Production of microcytic hypochromic anemia in puppies on synthetic diet deficient in rat antidermatitis factor (Vitamin B6). J. Nutrition, 1938, 16, 197.

7. Cartwright, G. E., Wintrobe, M. M., and Humphreys, S., St udies on anemia in swine due to pyridoxine deficiency, together with data on phenyl-hydrazine anemia. J. Biol. Chem., 1944, 153, 171.

8. McCall, K. B., Waisman, H. A., Elvehjem, C. A., and Jones, E. S., Study of pyridoxine and pantothenic acid deficiencies in monkey (Macaca mulatta). J. Nutrition, 1946, 31, 685.

9. Pehl, W., Uber das vitamin B6 (Adermin) mit klinischen versuchen bei der Saüglingsseborrhöe. Ztschr. f. Kinderh., 1940, 61, 613.

10. Jolliffe, N., Rosenblum, L. A., and Sawhill, J., Effects of pyridoxine (vitamin B6) on persistent adolescent acne. J. Invest. Dermat., 1942, 5, 143.

11. Wright, C. S., Samitz, M. H., and Brown, H., Vitam.n B6 (pyridoxine) in dermatology. Arch. Dermat. \& Syph., 1943, 47, 651.

12. Jolliffe, N., Clinical aspects of vitamin B deficiencies. Minnesota Med., 1940, 23, 542.

13. Rudesill, C. L., and Weigand, C. G., The treatment of Parkinson's disease with pyridoxine hydrochloride (vitamin B6 hydrochloride). J. Indiana M. A., 1941, 34, 355.

14. Antopol, W., and Schotland, C. E., The use of vitamin B6 in pseudohypertrophic muscular dystrophy. J. A. M. A., 1940, 114, 1058.

15. Vilter, R. W., Schiro, H. S., and Spies, T. D., Effect of synthetic vitamin B6 on the haemopoietic system of human beings. Nature, 1940, 145, 388.

16. Cantor, M. M., and Scott, J. W., Effect of vitamin B6 (pyridoxine) in the treatment of leucopenia and granulocytopenia of toxic origin in humans. Preliminary report. Science, 1944, 100, 545.

17. Hesseltine, H. C., Pyridoxine failure in nausea and vomiting of pregnancy. Am. J. Obst. \& Gynec., 1946, 51, 82.

18. Wells, J. J., and Popp, W. C., Pyridoxine hydrochloride in radiation sickness. Preliminary report. Proc. Staff Meet., Mayo Clin., 1947, 22, 482.

19. Spies, T. D., Bean, W. B., and Ashe, W. F., A note on the use of vitamin $\mathrm{B} 6$ in human nutrition. J. A. M. A., 1939, 112, 2414.

20. Smith, S. G., and Martin, D. W., Cheilosis successfully treated with synthetic vitamin B6. Proc. Soc. Exper. Biol. \& Med., 1940, 43, 660.

21. Hawkins, W. W., and Barsky, J., An experiment on human vitamin B6 deprivation. Science, 1948, 108, 284.

22. Bellamy, W. D., Umbreit, W. W., and Gunsalus, I. C., Function of pyridoxine; conversion of members of vitamin B6 group into codecarboxylase. J. Biol. Chem., 1945, 160, 461.

23. Schlenk, F., and Snell, E. E., Vitamin B6 and transamination. J. Biol. Chem., 1945, 157, 425.

24. Porter, C. C., Clark, I., and Silber, R. H., The effect of $\mathrm{B}$ vitamin deficiencies on tryptophan metabolism in the rat. Arch. Biochem., 1948, 18, 339.

25. Axelrod, H. E., Morgan, A. F., and Lepkovsky, S., Fate of tryptophane in pyridoxine-deficient and normal dogs. J. Biol. Chem., 1945, 160, 155.

26. Schneider, H., Steenbock, H., and Platz, B. R., Essential fatty acids, vitamin B6 and other factors in cure of rat acrodynia. J. Biol. Chem., 1940, 132, 539.

27. Wooley, D. W., Recent advances in the study of biological competition between structurally related compounds. Physiol. Rev., 1947, 27, 308.

28. Ott, W. H., Antipyridoxine activity of 2,4-dimethyl3-hydroxy-5-hydroxymethylpyridine in the chick. Proc. Soc. Exper. Biol. \& Med., 1946, 61, 125.

29. Mushett, C. W., Stebbins, R. B., and Barton, M. N., Studies on the pathologic effects produced by two analogues of pyridoxine. Tr. New York Acad. Sc., 1947, 9, 291.

30. Stoerk, H. C., The regression of lymphosarcoma implants in pyridoxine-deficient mice. J. Biol. Chem., 1947, 171, 437.

31. Gellhorn, A., and Jones, L. O., Pyridoxine deficient diet and desoxypyridoxine in the therapy of lym- 
phosarcoma and acute leukemia in man. Blood, 1949, 4, 60.

32. Huff, J. W., and Perlzweig, W. A., A product of oxidative metabolism of pyridoxine, 2-methyl3-hydroxy-4-carboxy-5-hydroxymethylpyridine (4pyridoxic acid). J. Biol. Chem., 1944, 155, 345.

33. Johnson, R. E., Sargent, F., Robinson, P. F., and Consolazio, F. C., Estimation of riboflavin, thiamine, and $\mathrm{N}^{1}$ methylnicotinamide. Rapid field method. Indust. \& Engin. Chem., Analyt. Ed., $1945,17,384$.

34. Huff, J. W., and Perlzweig, W. A., N'methylnico- tinamide, a metabolite of nicotinic acid in the urine. J. Biol. Chem., 1943, 150, 395.

35. Sure, B., and Ford, Z. W:, Jr., Vitamin interrelationships. II. Thiamine and riboflavin interrelationships in metabolism. J. Biol. Chem., 1942, 146, 241.

36. Cartwright, G. E., Wintrobe, M. M., Jones, P., Lauritsen, M., and Humphreys, S., Tryptophane derivatives in the urine of pyridoxine-deficient swine. Bull. Johns Hopkins Hosp., 1944, 75, 35.

37. Rinehart, J. F., and Greenberg, L. D., Arteriosclerosis and pyridoxine deficiency. Twenty-Second Scientific Session, Amer. Heart Assoc., June 3, 1949. 